\title{
Steroid B-Sitosterol Dari Kayu Batang Slatri (Calophyllum soulattri BURM. F)
}

\section{Soerya Dewi Marliyana*, Muhamad Widyo Wartono dan Ida Dahlia}

Program Studi Kimia, Fakultas Matematika dan Ilmu Pengetahuan Alam, Universitas Sebelas Maret, Jl. Ir. Sutami 36A, Surakarta, Indonesia, 57126

*email korespondensi: msoerya@staff.uns.ac.id

Received 14 October 2020, Accepted 4 February 2021, Published 15 March 2021

\begin{abstract}
Abstrak: Callophyllum soulattri Burm. F. merupakan salah satu spesies dari genus Callophyllum. Salah satu kandungan metabolit sekunder dari $C$. soulatrri adalah golongan senyawa steroid. Golongan steroid mempunyai beragam bioaktivitas antara lain antiinflamsi, antioksidan, antipoliferasi, antibakteri, antimalaria dan antikanker. Eksplorasi tumbuhan $C$. soulatrri masih terbatas oleh karena itu perlu dilakukan isolasi dan identifikasi metabolit sekunder dari tumbuhan tersebut. Satu senyawa golongan steroid telah berhasil diisolasi dan diidentifikasi dari ekstrak kayu batang $C$. soulattri. Metanol dipakai sebagai pelarut untuk maserasi, sedangkan fraksinasi dan pemurnian menggunakan metode Kromatgrafi Vakum Cair (KVC) yang dipantau dengan Kromatografi Lapis Tipis (KLT). Senyawa hasil isolasi ditentukan strukturnya dengan metode spektroskopi FTIR dan NMR $\left({ }^{1} \mathrm{H}\right.$ NMR, ${ }^{13} \mathrm{C}$ NMR, HSQC dan HMBC) serta dibandingkan dengan pustaka. Berdasarkan hasil interpretasi spektra FTIR dan NMR, senyawa yang berhasil diisolasi dari ekstrak metanol kayu batang $C$. soulatrri adalah $\beta$-sitosterol berbentuk padatan berwarna putih.
\end{abstract}

Kata kunci: Calophyllum soulattri Burm.F; kayu batang; $\beta$-sitosterol

Abstract. $\beta$-Sitosterol, A Steroid from Calophyllum soulattri Burm. F. Stem Wood Extract. Callophyllum soulattri Burm. F. is a species of the genus Callophyllum. One of the secondary metabolites of $C$. soulatrri is a class of steroid compound. The steroid class has a variety of bioactivity, including anti-inflammatory, antioxidant, anti-proliferative, antibacterial, antimalarial, and anticancer. The exploration of $C$. soulatrri is still limited, therefore it is necessary to isolate and identify the secondary metabolites from this plant. A steroid has been isolated and identified from the extract of the stem wood of $C$. soulattri. Methanol was used as a solvent for maceration; Fractionation and purification used the Liquid Vacuum Chromatgraphy (KVC) which was monitored by Thin Layer Chromatography (TLC). The structure of the isolated compound was determined using FTIR and NMR spectroscopy methods (1H NMR, 13C NMR, HSQC and HMBC) and compared with references. Based on interpretation of FTIR and NMR spectrum, the compound was isolated from the methanol extract of $C$. soulatrri stem wood was white crystalline $\beta$-sitosterol.

Keywords: Calophyllum soulattri Burm.F.; stem wood; $\beta$-sitosterol

\section{Pendahuluan}

Genus Calophyllum merupakan tumbuhan tropis yang banyak ditemukan di hutan dataran rendah dan memiliki sebaran terutama sebelah utara katulistiwa, di Indonesia dengan keragaman spesies terbanyak terdapat di Kalimantan, Sumatra dan Papua (Stevens et.al., 1980). Genus ini kaya akan berbagai metabolit sekunder yang mempunyai beragam bioaktivitas antara lain antiinflamatori (IC50 $14 \mu \mathrm{g} / \mathrm{mL}$ ) (Tsai et al, 2012), antimalaria (IC $\mathrm{I}_{50} 3,2 \pm 0,6 \mu \mathrm{g} / \mathrm{mL}$ ) (Hay 
et al, 2004, antimicrobial ( $\mathrm{IC}_{50} 0,3 \pm 0,1 \mu \mathrm{g} / \mathrm{mL}$ ) (Cuesta-Rubio et al, 2015), antikanker (IC 50 6,95 $\pm 0,47 \mu \mathrm{M}$ ) (Mah et al, 2015), antidiabetik ( $\mathrm{IC}_{50}$ 35,7 $\mu \mathrm{M}$ ) (Aminudin et al, 2015) dan antioksidan ( $\mathrm{IC}_{50} 0,11 \mathrm{mg} / \mathrm{mL}$ ) (Taher et al, 2010). Kandungan fitokimia yang telah dilaporkan dari tumbuhan genus Calophyllum bervariasi, dilihat dari golongan senyawa yang telah diisolasi terutama terdiri dari kromanon, santon, kumarin dan triterpenoid (Oliviera et al, 2014).

Slatri (Calophyllum soulatri) merupakan salah satu spesies Calophyllum yang tumbuh di Indonesia. Senyawa yang berhasil diisolasi dari kulit batang antara lain soulamarin (Ee et al, 2011), soulattrin (Siau et al, 2011), airlanggin A dan B yang merupakan benzofuran terprenilasi (Tanjung et al, 2018) dan calosubelinon (Lim et al, 2017). Kulit akar C. soulattri mengandung campuan senyawa $\beta$-sitosterol dengan stigmasterol yang termasuk ke dalam golongan steroid (Saputra et al, 2014). Eksplorasi $C$. soulatrri terutama pada bagian kayu batang masih belum banyak dilaporkan. Oleh karena itu artikel ini melaporkan senyawa steroid ( $\beta$-sitosterol) yang berhasil diisolasi dari kayu batang $C$. soulattri, sehingga memperbanyak informasi mengenai fitokimia tumbuhan $C$. soulattri yang selanjutnya dapat dijadikan sumber senyawa obat.

\section{Bahan dan Metode}

\subsection{Alat dan bahan}

Alat yang digunakan yaitu seperangkat alat Kromatigrafi Vakum Cair (KVC), Kromatografi Kolom Flash (KK Flash), seperangkat alat gelas penunjang, Spektrofotometer FTIR Shimadzu (Kyoto, Jepang) dan Spektrometer NMR 500 MHz Agilent (Santa Clara, USA). Bahan yang digunakan untuk pelarut yaitu kayu batang C. soulatrri dari Magelang, Jawa Tengah, metanol (teknis), n-heksana (teknis), etil asetat (teknis) dan aseton (teknis). Adsorben untuk kromatografi yaitu Silika gel 60 G (Merck; Darmstadt, Jerman), Silika gel 60 (0,04-0,063 mm) 230-400 mesh ASTM (Merck; Darmstadt, Jerman), Silika gel 60 (0,2-0,5 mm) (Merck; Darmstadt, Jerman) dan Plat TLC (alumunium berlapis silika gel $60 \mathrm{~F}_{254}$ 0,25 mm (Merck; Darmstadt, Jerman). Bahan penampak spot/noda Cerium (IV) (Merck; Darmstadt, Jerman) dan $\mathrm{H}_{2} \mathrm{SO}_{4}$ (Mallinckrodt).

\subsection{Metode}

Sebanyak $5 \mathrm{~kg}$ batang tanaman $C$. soulatri yang telah halus dan kering dimaserasi dalam metanol (35 L) pada temperatur kamar selama 3 x 24 jam. Maserat kemudian disaring dan filtrat diuapkan dengan evaporator sampai pekat kemudian dimasukkan dalam desikator untuk menguapkan sisa pelarut hingga dihasilkan ekstrak pekat metanol $40 \mathrm{~g}$.

Ekstrak metanol sebanyak $20 \mathrm{~g}$ difraksinasi dengan menggunakan Kromatografi Vakum Cair (KVC). Sampel setelah diimpregnasikan ke dalam silika gel kemudian dielusi dengan eluen $n$-heksana:etil asetat dengan tingkat kepolaran yang semakin bertambah yakni 9,5:0,5 $(2 x), 9: 1(4 x), 8,5 ; 1,5(4 x), 8: 2(2 x), 7: 3(2 x), 5: 5(2 x)$ dan 4:6 (1x); etil asetat (1x); dan aseton 
(1x). Eluen yang digunakan setiap elusi sebanyak $150 \mathrm{~mL}$. Hasil frakasinasi dengan KVC diperoleh sebanyak 19 fraksi. Masing-masing fraksi dianalisis dengan menggunakan kromatografi lapis tipis (KLT) dan dikelompokkan menjadi 3 fraksi yaitu fraksi 4-6 (F4, 0,509 g), fraksi 7-9 (F7, 0,476 g), fraksi 10-12 (F10, 0,360 g). Berdasarkan pola spot KLT, F4 (padatan berwarna kekuningan) dimurnikan untuk memperoleh isolat murni. F4 (0,509 g) yang berbentuk padatan berwarna kekuningan direkristalisasi menggunakan pelarut aseton dan diperoleh padatan putih sebanyak $193 \mathrm{mg}$. Selanjutnya dilakukan analisis dengan menggunakan spektroskopi FTIR dalam bentuk plat $\mathrm{KBr}$ dan $\mathrm{NMR}\left(\mathrm{CDCl}_{3}, 400 \mathrm{MHz}\right)$.

\section{Hasil dan Pembahasan}

Isolasi senyawa pada ekstrak kayu batang C. Soulattri diperoleh senyawa F4 berbentuk padatan berwarna putih, yang mempunyai titik leleh $134-136{ }^{\circ} \mathrm{C}$. Spektrum IR (KBr) dari senyawa F4 menunjukkan adanya gugus OH $\left(3605 \mathrm{~cm}^{-1}\right)$, olefinik siklik $\left(3413 \mathrm{~cm}^{-1}\right)$, serapan $=\mathrm{CH}$ pada $3005 \mathrm{~cm}^{-1}$ dan serapan C-H streching alifatis $\left(2927-2966 \mathrm{~cm}^{-1}\right)$. Serapan pada daerah $1455 \mathrm{~cm}^{-1}$ merupakan serapan olefinik, gem-geminal $\left(1362 ; 1221 \mathrm{~cm}^{-1}\right)$ dan $1092 \mathrm{~cm}^{-1}$ adalah serapan dari sikloalkana. Penentuan struktur F4 dianalisis lanjutan menggunakan $\mathrm{NMR}\left(\mathrm{CDCl}_{3}\right.$, ${ }^{1} \mathrm{H}$ NMR $400 \mathrm{MHz},{ }^{13} \mathrm{C}$ NMR $100 \mathrm{MHz}$ ). Selain dianalisis menggunakan NMR 1D juga dianalisis dengan NMR 2D yaitu Hetero-nuclear single-quantum correlation spectroscopy(HSQC) untuk mengetahui korelasi sinyal karbon dengan sinyal proton satu ikatan dan Hetero-nuclear multiple-bond correlation spectroscopy (HMBC) untuk mengetahui korelasi karbon dan proton dua sampai dengan tiga ikatan..

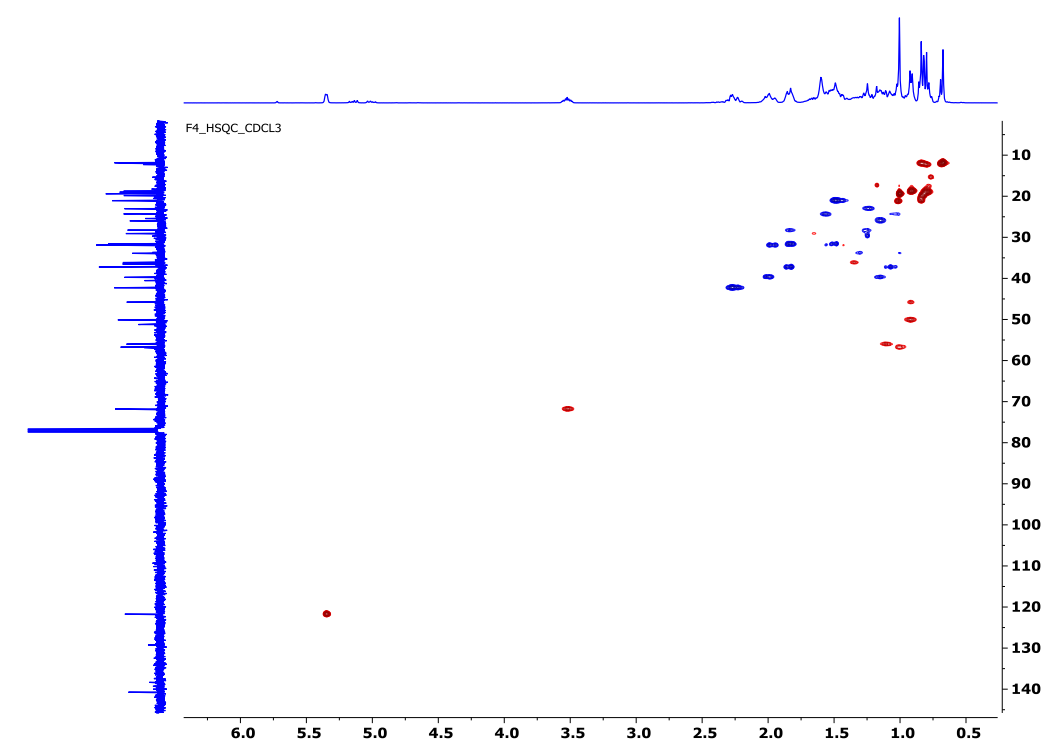

Gambar 1. Spektra Heteronuclear Single Quantum Coherence (HSQC) senyawa hasil isolasi F4 dari batang tanaman Calophyllum soulatri.

Spektrum ${ }^{1} \mathrm{H}$ NMR menunjukkan adanya sinyal proton $\left(\delta_{\mathrm{H}}\right)$ dari dua metil tersier $\delta_{\mathrm{H}}$ $1.00(3 \mathrm{H}, s, \mathrm{Me}-18)$ dan $0.68(3 \mathrm{H}, s, \mathrm{Me}-19)$, tiga metil sekunder pada $\delta_{\mathrm{H}} 0.92(3 \mathrm{H}, m$, , Me21), $0.86(3 \mathrm{H}, d, J=6,2 \mathrm{~Hz}, \mathrm{Me}-26)$, and $0.84(d, J=5,2 \mathrm{~Hz}, \mathrm{Me}-27)$ dan satu gugus metil 
primer $\delta_{\mathrm{H}} 0.86(m, \mathrm{Me}-29)$. Sinyal proton pada $\delta_{\mathrm{H}} 3,52(1 \mathrm{H}, m, \mathrm{H}-3)$ merupakan sinyal proton metin $\left(\mathrm{sp}^{3}\right)$ teroksigenasi sedangkan 5,34 $(m,, \mathrm{H}-6)$ gugus metin $\left(\mathrm{sp}^{2}\right)$. Sinyal proton $(m)$ pada $\delta_{\mathrm{H}} 5,01 ; 5,14 ; 2,26$ dan 2,00 merupakan sinyal proton olefinik. Spektrum ${ }^{13} \mathrm{C}$ NMR memperlihatkan adanya 29 puncak karbon, yang terdiri dari 2 puncak karbon $\mathrm{SP}^{2}$ dan 27 karbon $\mathrm{SP}^{3}$. Sinyal karbon pada $\delta_{\mathrm{C}}(\mathrm{ppm}) 140,7$ dan 121,7 adalah sinyal karbon ikatan rangkap (C5, C6). Nilai geseran $\delta_{\mathrm{C}}$ pada daerah $\delta_{\mathrm{C}}$ 11,8-70,8 ppm merupakan sinyal karbon alkana yang terdiri dari karbon metilen $\left(\mathrm{CH}_{2}\right)$ dan karbon metil $\left(\mathrm{CH}_{3}\right)$. Sedangkan sinyal karbon $\mathrm{C}-\mathrm{OH}$ terletak pada daerah 70,8 ppm. Berdasarkan penelusuran literatur, sinyal proton dan karbon pada geseran tersebut sesuai dengan tipe kerangka steroid stigmastan (Cayme \& Ragasa, 2004; Farabi et al, 2017; Pierre et al, 2015).

Korelasi proton-karbon dua dimensi dijelaskan melalui data HSQC. Spektrum HSQC dari senyawa F4 (Gambar 1) menunjukkan adanya korelasi dari proton dengan karbon satu ikatan yang secara ringkas dapat ditampilkan pada Tabel 1. Berdasarkan data seperti tercantum pada Tabel 1 terdapat sinyal karbon yang tidak mempunyai hubungan korelasi. Hal ini menunjukkan bahwa sinyal tersebut merupakan sinyal dari karbon kuarterner seperti pada sinyal karbon alkena pada $\delta_{\mathrm{C}} 140,7 \mathrm{ppm}$ dan $\mathrm{C}$ kuartener juga terdapat pada $\delta_{\mathrm{C}} 36,5$ dan 42,3 ppm.

Tabel 1. Korelasi proton dan karbon dari data Heteronuclear Single Quantum Coherence (HSQC) dan jenis atom karbon. ) senyawa hasil isolasi F4 dari batang tanaman Calophyllum soulatri.

\begin{tabular}{cccccc}
\hline$\delta \mathbf{C}$ & $\boldsymbol{\delta H}$ & $\mathbf{K e t}$ & $\boldsymbol{i}$ & $\boldsymbol{\delta}$ & $\mathbf{K e t}$ \\
\hline 140,7 & - & $\mathrm{C}$ & 31,9 & 1,$99 ; 1,56(m)$ & $\mathrm{CH}_{2}$ \\
121,7 & 5,34 & $\mathrm{CH}$ & 31,6 & 1,$95 ; 1,79 ; 1,5(m)$ & $\mathrm{CH}_{2}$ \\
71,8 & $5,71(m)$ & $\mathrm{CH}$ & 29,1 & $1,64(m)$ & $\mathrm{CH}$ \\
56,7 & $0,98(m$ & $\mathrm{CH}$ & 28,3 & 1,$85 ; 1,21(t)$ & $\mathrm{CH}_{2}$ \\
56,0 & $1,08(m)$ & $\mathrm{CH}$ & 26,0 & $1,13(m)$ & $\mathrm{CH}_{2}$ \\
51,2 & $1,51(m)$ & $\mathrm{CH}$ & 24,3 & 1,$54 ; 1,06(m)$ & $\mathrm{CH}_{2}$ \\
50,1 & $0,91(m)$ & $\mathrm{CH}$ & 23,0 & $1,23(m)$ & $\mathrm{CH}_{2}$ \\
45,8 & $0,92(m)$ & $\mathrm{CH}$ & 21,1 & $1,49(m)$ & $\mathrm{CH}_{2}$ \\
42,3 & - & $\mathrm{C}$ & 19,8 & $0,86(d, 6,2)$ & $\mathrm{CH}_{3}$ \\
42,2 & $2,26(m)$ & $\mathrm{CH}$ & 19,4 & $1,00(s)$ & $\mathrm{CH}_{3}$ \\
39,7 & 1,$15 ; 2,00(m)$ & $\mathrm{CH}$ & 19,0 & $0,84(d, 5,2)$ & $\mathrm{CH}_{3}$ \\
37,2 & 1,$06 ; 1,83(t)$ & $\mathrm{CH}$ & 18,8 & $0,76(m)$ & $\mathrm{CH}_{3}$ \\
36,5 & - & $\mathrm{C}$ & 12,0 & $0,80(m)$ & $\mathrm{CH}_{3}$ \\
36,1 & $1,34(m)$ & $\mathrm{CH}$ & 11,9 & $0,67(s)$ & $\mathrm{CH}_{3}$ \\
33,9 & 1,$27 ; 1,02(m)$ & $\mathrm{CH}$ & - & & \\
\hline
\end{tabular}

Spektra HMBC dari senyawa F4 (Gambar 2) menunjukkan hubungan hubungan protonkarbon tetangga yang berjarak antara dua sampai tiga ikatan, korelasi tersebut ditunjukkan 
dengan suatu sinyal, sehingga dengan adanya hubungan korelasi tersebut dapat mengetahui posisi karbon kuarterner.

Berdasarkan data ${ }^{13} \mathrm{C}$ NMR, ${ }^{1} \mathrm{H}$ NMR dan HMBC menunjukkan bahwa terdapat gugus geranil dan gugus hidroksi pada senyawa F4. Proton metil $\delta_{\mathrm{H}} 0,76 \mathrm{ppm}$ pada F4 memiliki korelasi dengan karbon $\delta_{\mathrm{C}} 33,9 ; 36,1$ dan 56,0 ppm. Proton $\delta_{\mathrm{H}} 1,34$ ppm berkorelasi dengan karbon pada $\delta_{\mathrm{C}} 18,8$ dan $33,9 \mathrm{ppm}$. Proton metilen pada $\delta_{\mathrm{H}} 1,85 \mathrm{ppm}$ memiliki korelasi dengan $\delta_{\mathrm{C}} 36,1$ dan 56,0 ppm. Sinyal proton pada $\delta_{\mathrm{H}} 1,85 \mathrm{ppm}$ memiliki korelasi dengan karbon-karbon pada $\delta_{\mathrm{C}} 36,1 ; 56,0$ dan $42,3 \mathrm{ppm}$. Korelasi HMBC proton dengan karbon antara kerangka steroid dengan gugus geranil pada senyawa F4 ditunjukkan pada Gambar 3.

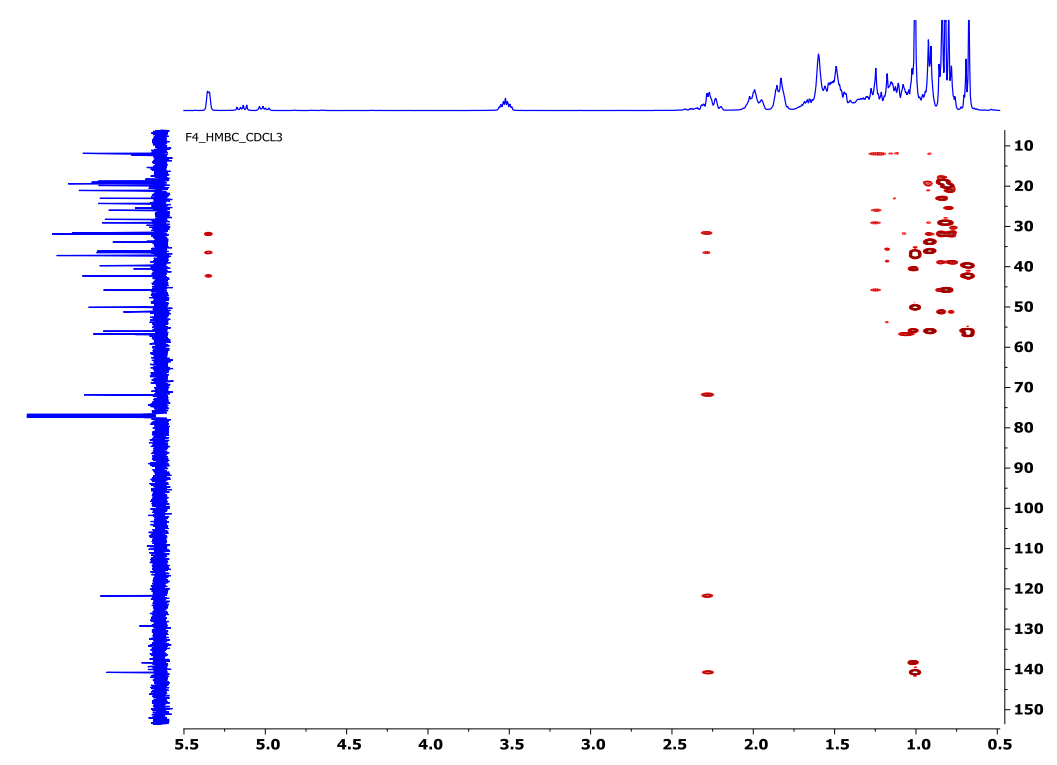

Gambar 2. Spektra Heteronuclear Multiple Bond Correlation (HMBC) senyawa hasil isolasi F4 dari batang tanaman Calophyllum soulatri.

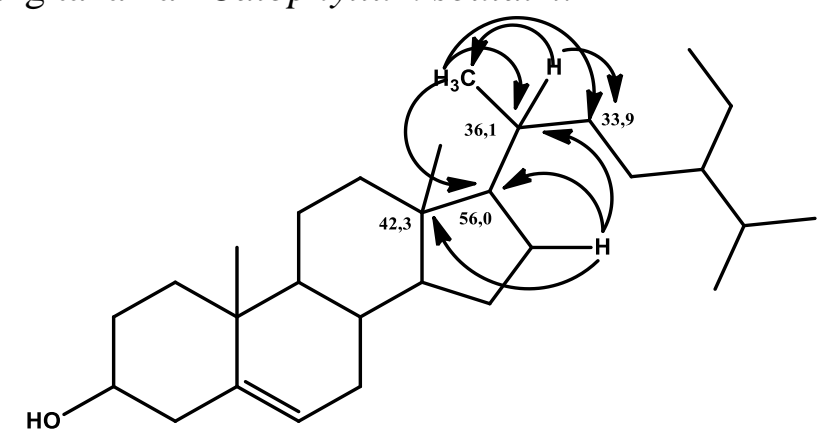

Gambar 3. Korelasi Heteronuclear Multiple Bond Correlation (HMBC) yang penting antara proton dengan karbon pada kerangka steroid dengan gugus geranil pada senyawa hasil isolasi F4 dari batang tanaman Calophyllum soulatri.

Hasil analisis data baik data spektrum IR dan NMR (1H NMR, 13C NMR, HSQC, HMBC) selanjutnya dibandingkan dengan data literatur (Tabel 2) dan terkonfirmasi bahwa F4 mempunyai kemiripan dengan struktur $\beta$-sitosterol (Pierre et al, 2015; Katja et al, 2019). Senyawa $\beta$-sitosterol yang berhasil diisolasi dari ekstrak metanol kayu batang $C$. soulatrri bukanlah senyawa baru. Senyawa ini juga ditemukan pada spesies lain seperti pada 
Odontonema strictum dan Chisocheton celebicus (Pierre et al, 2015; Katja et al, 2019). Struktur $\beta$-sitosterol seperti ditampilkan pada Gambar 4.

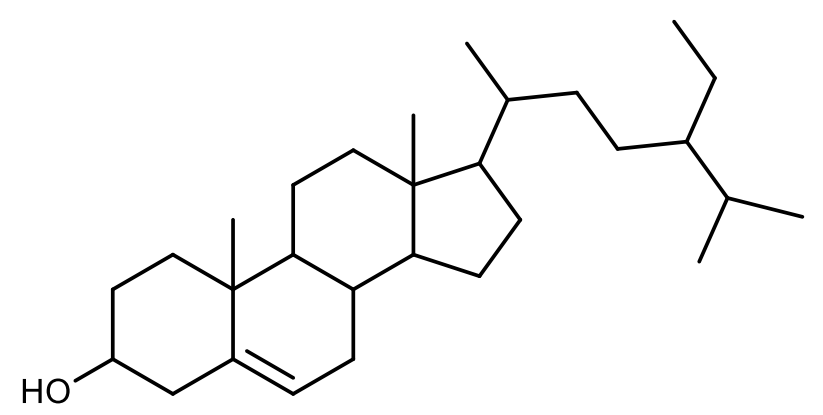

Gambar 4. Struktur senyawa $\beta$-sitosterol hasil isolasi dari batang tanaman Calophyllum soulatri.

Tabel 2. Perbandingan Data NMR Isolat F4 Eksperimen dengan Literatur (F4*). Senyawa F4 : diukur dalam $\mathrm{CDCl}_{3}, 400 \mathrm{MHz}\left({ }^{1} \mathrm{H}\right)$ dan $100 \mathrm{MHz}\left({ }^{13} \mathrm{C}\right)$. Senyawa F4*: diukur dalam $\mathrm{CDCl}_{3}, 400 \mathrm{MHz} / 500 \mathrm{MHz}\left({ }^{1} \mathrm{H}\right)$ dan $100 \mathrm{MHz} / 125 \mathrm{MHz}\left({ }^{13} \mathrm{C}\right.$ ) (Pierre et al, 2015; Katja et al, 2019).

\begin{tabular}{|c|c|c|c|c|}
\hline \multirow{2}{*}{ No. $C$} & \multicolumn{2}{|c|}{$\delta_{\mathrm{H}}($ ppm) (multiplisitas, $J$ dalam Hz) } & \multicolumn{2}{|c|}{$\delta \mathrm{C}(\mathrm{ppm})$} \\
\hline & F4 & F4* & F4 & F4* \\
\hline 1 & $1,83(\mathrm{~m})$ & $1,83(\mathrm{~m})$ & 37,2 & 37,3 \\
\hline 2 & $1,95(m)$ & $1,90(\mathrm{~m})$ & 31,6 & 31,9 \\
\hline 3 & $3,52(m)$ & $3,52(\mathrm{~m})$ & 71,8 & 72,0 \\
\hline 4 & $2,26(\mathrm{~m})$ & $2,23(\mathrm{~m})$ & 42,3 & 42,3 \\
\hline 5 & - & - & 140,7 & 140,7 \\
\hline 6 & $5,34(m)$ & $5,35(m)$ & 121,7 & 121,8 \\
\hline 7 & $1,99(m)$ & $1,99(m)$ & 31,9 & 32,1 \\
\hline 8 & $1,51(m)$ & $1,69(m)$ & 31,9 & 32,1 \\
\hline 9 & $0,91(m)$ & $0,96(\mathrm{~m})$ & 50,1 & 50,1 \\
\hline 10 & - & - & 36,5 & 36,7 \\
\hline 11 & $1,49(m)$ & $1,47(m)$ & 21,1 & 21,1 \\
\hline 12 & $2,00(\mathrm{~m})$ & $1,50(m)$ & 39,7 & 39,7 \\
\hline 13 & - & - & 42,3 & 42,3 \\
\hline 14 & $0,98(m)$ & $0,95(m)$ & 56,7 & 56,9 \\
\hline 15 & $1,54(m)$ & $1,54(m)$ & 24,3 & 24,3 \\
\hline 16 & $1,85(m)$ & $1,62(\mathrm{~m})$ & 28,3 & 28,4 \\
\hline 17 & $1,08(m)$ & $1,10(m)$ & 56,0 & 56,0 \\
\hline 18 & $0,67(s)$ & $1,00(s)$ & 11,9 & 12,0 \\
\hline 19 & $1,00(s)$ & $0,86(s)$ & 19,4 & 19,8 \\
\hline 20 & $1,34(m)$ & $1,36(m)$ & 36,1 & 36,2 \\
\hline 21 & $0,92(m)$ & $0,92(m)$ & 18,8 & 19,2 \\
\hline 22 & $1,27(\mathrm{~m})$ & $1.17(\mathrm{~m})$ & 33,9 & 34,0 \\
\hline 23 & $1,13(m)$ & $1,23(m)$ & 26,0 & 26,2 \\
\hline 24 & $0,92(m)$ & $1,01(m)$ & 45,8 & 45,8 \\
\hline 25 & $1,65(m)$ & $1,60(m)$ & 29,1 & 29,3 \\
\hline 26 & $0,86(d, 6,2)$ & $0,83(d, 6,5)$ & 19,8 & 19,6 \\
\hline 27 & $0,84(d, 5,2)$ & $0,79(d, 5,2)$ & 19,0 & 18,8 \\
\hline 28 & $1,23(m)$ & $1,30(m)$ & 23,0 & 23,2 \\
\hline 29 & $0,80(m)$ & $0,83(\mathrm{~m})$ & 12,0 & 12,0 \\
\hline
\end{tabular}




\section{Kesimpulan}

Golongan senyawa steroid yaitu $\beta$-sitosterol dengan rumus molekul $\mathrm{C}_{29} \mathrm{H}_{50} \mathrm{O}$ berbentuk padatan berwarna putih telah berhasil diisolasi dan diidentifikasi dari ekstrak metanol kayu batang $C$. soulattri. Hasil ini dapat digunakan untuk menambah data base dan sumber senyawa obat yang berhasil diisolasi dari $C$. soulatrri.

\section{Ucapan Terimakasih}

Penelitian ini didanai oleh Hibah Grup Riset dana PNBP tahun 2020 Universitas Sebelas Maret, dengan No. Kontrak: 452/UN27.21/PN/2020.

\section{Deklarasi Konflik Kepentingan}

Semua penulis menyatakan tidak ada konflik kepentingan terhadap naskah ini.

\section{Daftar Pustaka}

Aminudin, N. I., Ahmad, F., Taher, M., Zulkifli, R. M. (2015). $\alpha$-Glucosidase and 15lipoxygenase inhibitory activities of phytochemicals from Calophyllum symingtonianum. Natural Product Communications, 10: pp.1585-1588. 10.1177/1934578X1501000925.

Cayme, J., dan Ragasa, C. (2004). Structure elucidation of $\beta$-stigmasterol and $\beta$-sitosterol from Sesbania grandiflaora (Linn). Pers. and $\beta$ - carotene from Heliotropium indicum Linn by NMR spectroscopy. Journal of Kimika, 20: pp.5-12. 10.26534/kimika.v20i1.5-12.

Tsai, S. C., Liang, Y. H., Chiang, J. H., Liu, F. C., Lin, W. H., Shu-Jen Chang, S. J., Lin, W. Y., Wu, C. H., And Weng, J. R. (2012). Anti-Inflammatory Effects of Calophyllum Inophyllum L. In Raw264.7 Cells. Oncology Reports, 28: pp. 1096-1102. 10.3892/Or.2012.1873.

Ee, G. C. L., Mah, S. H., Teh, S. S., Rahmani, M., Go, R., and Taufiq-Yap, Y. H. (2011). Soulamarin, a New Coumarin from Stem Bark of C. soulattri. Molecules. 16: pp.97219727. 10.3390/molecules16119721.

Farabi, K., Harneti, D., Nurlelasari, Maharani, R., Hidayat, A. C., Supratman, U., Awang, K., Shiono, Y. (2017). Cytotoxic steroids from the bark of aglaia argentea (Meliaceae). Chiang Mai University Journal. Natural Sciences. 16(4): pp.293-306. 10.12982/CMUJNS.2017.0024

Hay, A.E., Hélesbeux, J.J., Duval, O., Labaïed, M., Grellier, P., Richomme, P. (2004). Antimalarial xanthones from Calophyllum caledonicum and Garcinia vieillardii. Life Sciences, 75(25): pp. 3077-3085. 10.1016/j.lfs.2004.07.009.

Katja, D. G., Harneti, D., Mayanti, T., Nurlelasari, Maharani, R., Shiono, Y., Supratman, U. (2019). Cytotoxic Steroids From The Stem Bark of Chisocheton celebicus KOORD. Jurnal Kimia Valensi, 5(2): pp.143-148. 10.15408/jkv.v5i2.12132.

Lim, C. K., Hemaroopini, S., Say, Y. H., and Jong, Y. M. (2017). Cytotoxic Compounds from the Stem Bark of Calophyllum soulattri, Natural Product Communications, 12 (9), pp. 1439-1471.

Mah, S.H., Ee, G.C.L., Teh, S.S., Sukari, M.A. (2015). Calophyllum inophyllum and Calophyllum soulattri source of anti-proliferative xanthones and their structure-activity relationships. Natural Product Research, 29(1): pp. 98-101. 10.1080/14786419.2014.959949.

Pierre, L. L. dan Moses, M. N. (2015). Isolation and Characterisation of Stigmasterol and B Sitosterol from Odontonema Strictum (Acanthaceae). Journal of Innovations in Pharmaceuticals and Biological Sciences. 2(1): pp. 88-96. 10.13140/RG.2.1.3689.7365. 
Saputra, D. E., Handayani, N., Wartono, M. W. (2014). Isolasi dan Identifikasi Campuran Senyawa $\beta$-Sitosterol dan Stigmasterol dari Kulit Akar Slatri (Calophyllum soulattri Burm. F). ALCHEMY Jurnal Penelitian Kimia, 10(1): pp. 87-93.

Siau, H. M., Ee, G.C.L., Mawardi, R., Yun, H. T., Mohd, A. S., Soek, S. T. (2011). A New Pyranoxanthone from Calophyllum soulattri. Journal Molecules, 16: pp. 3999-4004. 10.3390/molecules16053999.

Taher, M., Attoumani, N., Susanti, D., Ichwan, S.J.A., Ahmad, F. (2010). Antioxidant activity of leaves of Calophyllum rubiginosum. American Journal of Applied Sciences, 7(10): 1305-1309. 10.3844/ajassp.2010.1305.1309

Tanjung, M., Rachmadiarti, F., Prameswari, A., Agyani, V.U.W., Saputri, R.D., Tjahjandarie, Tj.S., \& Syah, Y.M. (2018). Airlanggins A-B, two new isoprenylated benzofuran-3-ones from the stem bark of Calophyllum soulattri. Natural Product Research, 32(13): pp. 1493-1498. 10.1080/14786419.2017.1380027.

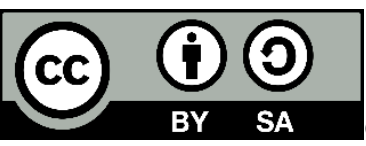
(https://creativecommons.org/licenses/by-sa/4.0/). 